\title{
Global standards for global health in a globalized economy!
}

\author{
Nino Künzli $\cdot$ Meltem Kutlar Joss $\cdot$ Emily Gintowt
}

Received: 12 August 2015/ Accepted: 12 August 2015/Published online: 21 August 2015

(C) Swiss School of Public Health 2015

The global health community is dedicated to end unnecessary, preventable and treatable inequities in the global health status (Koplan et al. 2009). Its research community provides the scientific evidence needed for policy making toward this goal. An overwhelming global scientific literature leaves no doubts: anthropogenic air pollution is one of the major causes of morbidities and premature death on the globe, with 7 million deaths attributable to indoor and/ or outdoor air pollution; this risk factor ranks third after high blood pressure-which, in part, is also a consequence of air pollution-and smoking (WHO 2014; Fuks et al. 2014). Using the Global Burden of Disease (GBD) website (GBD 2010) the years of lives lost (YLL) due to air pollution-defined as the sum of household pollution, ambient air pollution, and ozone-add up to $\sim 174$ Million YLL every year. This environmental factor ranks second after the 200 Mio YLL attributed to dietary risks. It is followed by the impact of high blood pressure (167 Mio YLL) and smoking (138 Mio YLL). The contribution of air pollution is the sum of $\sim 100$ Mio YLL attributed to household air pollution due to biomass combustion and 74 Mio YYL due to ambient air pollution. The latter is very similar to the global 76 Mio YYL attributed to malaria, which is still the fifth-ranked disease after ischemic heart diseases, lower respiratory diseases, stroke, and diarrheal diseases (Wang

This editorial is part of the special issue "Driving the Best Science to Meet Global Health Challenges" edited on the occasion of the 9th European Congress on Tropical Medicine and International Health 2015

N. Künzli $(\square) \cdot$ M. K. Joss · E. Gintowt

Swiss Tropical and Public Health Institute, Basel Switzerland and University of Basel, Socinstrasse 57, P.O. Box, 4002 Basel, Switzerland

e-mail: nino.kuenzli@unibas.ch et al. 2012). Whereas air pollution research has been primarily driven by projects conducted in wealthier Western countries, studies emerging from low and middle income countries not only confirm adverse findings in general terms but show that air pollution is much worse in those countries (Brauer et al. 2012).

Global health is not only about understanding the causes of health and disparities in health of people worldwide, but also about providing solutions to these challenges (Koplan et al. 2009). In case of air pollution, the good news is that it is an unnecessary, largely preventable and treatable inequity. Indeed, most Western countries experienced substantial improvements in air quality over the past 40 years and seminal studies conducted over decades confirm direct health benefits of clean air policies (Brauer et al. 2012). Those policies are driven by the WHO Guidelines for Clean Air, which are based on the global scientific literature, and are set to protect people's health (WHO 2006). A recent review on behalf of the European Union reaffirms that those targets are supported by more recent research and that the upcoming revision of the WHO air quality guidelines may, if anything, call for tighter targets (Héroux et al. 2015). As of May 26, 2015, the WHO Assembly adopted its first international resolution aimed at clean skies among its 194 member states (WHO 2015).

Thus, the question emerges: where do member states stay in setting clean air standards? The answer is sobering. Many governments all across the globe continue to ignore the science-based call for clean air. Instead of setting national air quality standard goals to protect peoples' health - and thus to reduce the enormous costs related to the air pollution attributable burden of disease- the advice of biased stakeholders count more strongly than the science-based guidelines of WHO and the health needs of the people. This results in inconsistent policy making and the 
continued promotion of increasing environmental inequity instead of the move toward equal rights to live in an environment that supports good health. Whereas research tackles the question of inequity of exposure to air pollution within cities and countries (Benmarhnia et al. 2014), policy discrepancies between countries are not much discussed. Table 1 exemplifies the result of the inconsistencies and ignorance of policy makers showing current air quality standards set for particulate matter up to 10 and up to $2.5 \mu \mathrm{m}$ in aerodynamic diameter (PM10 and PM2.5). The vast majority of countries fail to comply with the values proposed by WHO. The situation is particularly odd in the European Union (EU). Land mark studies funded by the EU confirm the evidence of adverse effects of ambient air pollution even among people with home outdoor concentrations below the current guideline values set by WHO (Beelen et al. 2014). In line with this evidence, EU has set a range of rather pro-active standards to control emissions (e.g., the Euro VI regulations) and the EU Commission considers even more rigorous standards (ERS 2015). However, EU policy makers fail to set science-based ambient air quality standards to protect public health. As shown in Table 1, the PM10 annual mean standard is set twice as high as the one proposed by WHO; thus, the EU Commission accepts a very large-though preventableburden of death and disease. They ignore that air quality standards are a major incentive to invest in solutions. Air quality standards provide targets for all national and local authorities who are in charge of clean air management plans. Those plans are indeed tailored to reach compliance with those standards. Authorities across Europe clearly lack incentives to comply with the air quality targets proposed by WHO.

From a global health perspective, the consequences of unequal standard setting are unacceptable. As shown in the global air quality models developed for the GBD (2010) project (Brauer et al. 2012), inequities in environmental policies lead to ever-increasing inequities in air quality. Indeed most of the regions in the world with the worst air quality in 1990 experienced a deterioration of air quality by 2010. Instead, global regions with better air quality in 1990 have seen further improvements due to the implementation of clean air policies to reach science-based air quality standards. The consequences of these trends can be seen in the comparison of the country-specific ranking of the risk factors that determine the national burden of disease (GBD 2010). The countries where air pollution (defined as the sum of household and ambient pollution-including ozone) has become the top leading cause of death are without exception countries in Asia (e.g., Afghanistan, Bangladesh, Laos, India) or Africa (Benin, Congo, Gambia, Ghana). Such trends are driven by the lack of governments to set adequate air quality standards and by globally active
Table 1 Current (August 2015) long-term (annual mean) Air Quality Standards set for ambient concentrations of particulate matter PM10 and/or PM2.5 in various countries [or states/cities $(>)$ ] across the world

\begin{tabular}{|c|c|c|}
\hline Country or agency & $\mathrm{PM}_{10} \mu \mathrm{g} \mathrm{m}^{-3}$ & $\mathrm{PM}_{2.5} \mu \mathrm{g} \mathrm{m}^{-3}$ \\
\hline Reference: WHO & 20 & 10 \\
\hline \multicolumn{3}{|l|}{ Africa } \\
\hline Kenya & 50 & 35 \\
\hline South Africa & 50 & 25 \\
\hline Tanzania & $60-90$ & N/A \\
\hline \multicolumn{3}{|l|}{ Central America } \\
\hline Costa Rica & 50 & N/A \\
\hline El Salvador & 50 & 15 \\
\hline Jamaica & 50 & N/A \\
\hline Nicaragua & 50 & N/A \\
\hline Panama & 50 & N/A \\
\hline Dominican Republic & 50 & 15 \\
\hline \multicolumn{3}{|l|}{ North America } \\
\hline Canada & N/A & 10 \\
\hline$>$ British Columbia & N/A & 10 \\
\hline Mexico & 40 & 12 \\
\hline Puerto Rico & N/A & 15 \\
\hline USA & 50 & 15 \\
\hline$>$ California & 20 & 12 \\
\hline \multicolumn{3}{|l|}{ South America } \\
\hline >Buenos Aires & 50 & 15 \\
\hline Bolivia & 50 & N/A \\
\hline$>\mathrm{La} \mathrm{Paz}$ & 20 & 10 \\
\hline Brazil & 50 & N/A \\
\hline Chile & 50 & 20 \\
\hline Colombia & 50 & 25 \\
\hline Ecuador & 50 & 15 \\
\hline Peru & 50 & N/A \\
\hline Venezuela & 50 & N/A \\
\hline \multicolumn{3}{|l|}{ Asia/Oceania } \\
\hline Australia & N/A & 8 \\
\hline Bangladesh & 50 & 15 \\
\hline $\begin{array}{l}\text { China (residential } \\
\text { areas) }\end{array}$ & 100 & N/A \\
\hline Hong Kong SAR & 55 & N/A \\
\hline India & 60 & 40 \\
\hline Iran & 20 & 10 \\
\hline Israel & 50 & 25 \\
\hline Japan & N/A & 15 \\
\hline Malaysia & 50 & N/A \\
\hline Philippines & 60 & N/A \\
\hline Republic of Korea & 50 & N/A \\
\hline Singapore & N/A & 15 \\
\hline South Korea & 50 & 25 \\
\hline Sri Lanka & 50 & 25 \\
\hline Taiwan & 65 & N/A \\
\hline
\end{tabular}


Table 1 continued

\begin{tabular}{lll}
\hline Country or agency & $\mathrm{PM}_{10} \mu \mathrm{g} \mathrm{m}^{-3}$ & $\mathrm{PM}_{2.5} \mu \mathrm{g} \mathrm{m}^{-3}$ \\
\hline Thailand & 50 & 25 \\
Uzbekistan & 50 & N/A \\
Vietnam & 50 & 25 \\
Europe & & \\
EU & 40 & 25 \\
Switzerland & $\mathbf{2 0}$ & 10 under \\
& & consideration \\
Turkey & 60 & N/A \\
\hline
\end{tabular}

Standards set in bold are within $20 \%$ of the science-based values as proposed by WHO to protect public health

N/A or countries not listed: no policies could be identified. For other national air quality standards and for references to the National policies: see the website of the Swiss Tropical and Public Health Institute (http://ludok.swisstph.ch)

companies who seek to profit from the policy vacuum in those countries through the outsourcing of polluting industries to countries with inadequate policies.

The globalized economy must be accompanied by globalized clean air policies. The science-based guideline values proposed by WHO are not negotiable. All countries should adopt those values as the unconditional targets for clean air policies. The current situation of a globalized economy combined with environmental policy making driven by lobbyist instead of the public health needs must be of particular concern for low and middle income countries (LMICs) where multinational companies capitalize on lax clean air regulations. LMIC economies cannot afford the large and costly burden of diseases due to poor air quality. Globally harmonized clean air policies will strongly contribute to ending the outsourcing of pollution from high to low income countries. It is-for exampleunacceptable that cars sold in Europe must comply with Euro VI emission norms, whereas car makers (including Europeans) continue to put heavily polluting trucks and cars on the streets of countries with lax policies.

In sum, global health calls for globalized science-based clean air regulations; thus, all governments should adopt the WHO Guideline values as nationally binding clean air standards!

\section{References}

Beelen R, Raaschou-Nielsen O, Stafoggia M, Andersen ZJ, Weinmayr G, Hoffmann B et al (2014) Effects of long-term exposure to air pollution on natural-cause mortality: an analysis of 22 European cohorts within the multicentre ESCAPE project. Lancet 383(9919):785-795

Benmarhnia T, Rey L, Cartier Y, Clary CM, Deguen S, Brousselle A (2014) Addressing equity in interventions to reduce air pollution in urban areas: a systematic review. Int $\mathrm{J}$ Public Health 59(6):933-944

Brauer M, Amann M, Burnett RT, Cohen A, Dentener F, Ezzati M et al (2012) Exposure assessment for estimation of the global burden of disease attributable to outdoor air pollution. Environ Sci Technol 46(2):652-660

European Respiratory Society (ERS) (2015) European Parliament takes first step towards ambitious air legislation 2015. http:// www.ersnet.org/eu-affairs/item/5069-european-parliamenttakes-first-step-towards-ambitious-air-legislation.html

Fuks KB, Weinmayr G, Foraster M, Dratva J, Hampel R, Houthuijs D et al (2014) Arterial blood pressure and long-term exposure to traffic-related air pollution: an analysis in the European Study of Cohorts for Air Pollution Effects (ESCAPE). Environ Health Perspect 122(9):896-905

Global Burden of Diseases (GBD) (2010) Institute for Health Metrics and Evaluation 2013. http://vizhub.healthdata.org/irank/heat.php

Héroux M, Anderson R, Atkinson R, Brunekreef B, Cohen A, Forastiere F et al (2015) Quantifying the health impacts of ambient air pollutants: recommendations of a WHO/Europe project. Int J Public Health. doi:10.1007/s00038-015-0690-y

Koplan JP, Bond TC, Merson MH, Reddy KS, Rodriguez MH, Sewankambo NK et al (2009) Towards a common definition of global health. Lancet 373(9679):1993-1995

Wang H, Dwyer-Lindgren L, Lofgren KT, Rajaratnam JK, Marcus JR, Levin-Rector A et al (2012) Age-specific and sex-specific mortality in 187 countries, 1970-2010: a systematic analysis for the Global Burden of Disease Study 2010. Lancet 380(9859):2071-2094

World Health Organization (WHO) (2006) Air quality guidelines for particulate matter, ozone, nitrogen dioxide and sulfur dioxideglobal update 2005 Geneva: WHO Office for Europe. http:// www.euro.who.int/_data/assets/pdf_file/0005/78638/E90038. pdf

World Health Organization (WHO) (2014) 7 million premature deaths annually linked to air pollution. http://www.who.int/ mediacentre/news/releases/2014/air-pollution/en/

World Health Organization (WHO) (2015) Air quality and health resolution adopted at the sixty-eighth World Health Assembly.http://www.euro.who.int/en/health-topics/environment-andhealth/air-quality/news/news/2015/05/air-quality-and-healthresolution-adopted-at-the-sixty-eighth-world-health-assembly 